\section{France boosts nuclear physics}

by Roger Woodham

A NEW experimental facility for 'low energy' nuclear physicists, to be known as the Grand Accelerateur National a Ions Lourds (GANIL), will be included in the French Seventh Plan which covers the years 1976-80. It will cost about $£ 20$ million, should be in operation before 1980 and is to be built just outside Caen in Normandy.

As well as being part of the French government's strategy for livening up the French economy by authorising spending on new scientific projects during the next five years, the Caen decision also has implications for the recently acquired French interest in regional policy. With the mood in France at present much in favour of decentralisation, the Délégation Générale à la Recherche Scientifique et Technique (DGRST) has taken the first tentative step towards some sort of regional policy in science by giving the green light to GANIL.

Instead of choosing to build the new accelerator complex in the vicinity of Paris, perhaps at Saclay or Orsay, the DGRST and the Minister of Industry and Research, M. Michel d'Ornano, settled on Caen-a somewhat surprising selection which was not on the list of places like Grenoble, Strasbourg, Lyon and Bordeaux which have been widely canvassed during the past year or so. Cynics like to point out that M d'Ornano is Mayor of Deauville (not far from Caen) and was until last year President of the Regional Council of Lower Normandy. The fact is, however, that Caen is only two hours by a fast train service from Paris and will therefore be easily accessible to nuclear physicists from other countries, a significant consideration given that the French see GANIL as an important international facility.

The GANIL project, which will make available beams of heavy ions ranging from carbon to uranium at energies higher than is or will be possible with machines elsewhere, is the brainchild of a coordinating committee set up by the DGRST in 1972 to look at the whole matter of French support for nuclear and elementary particle physics. (In France these activities come under the auspices of the Commissariat à l'Energie Atomique (CEA) and the Institut National de Physique Nucléaire and et de Physique des Particules, the latter being an umbrella organisation colloquially known as IN2P3 and covering all nuclear and particle physics activity in university laboratories and those of the CNRS (Centre National de la Recherche Scientifique).) GANIL was

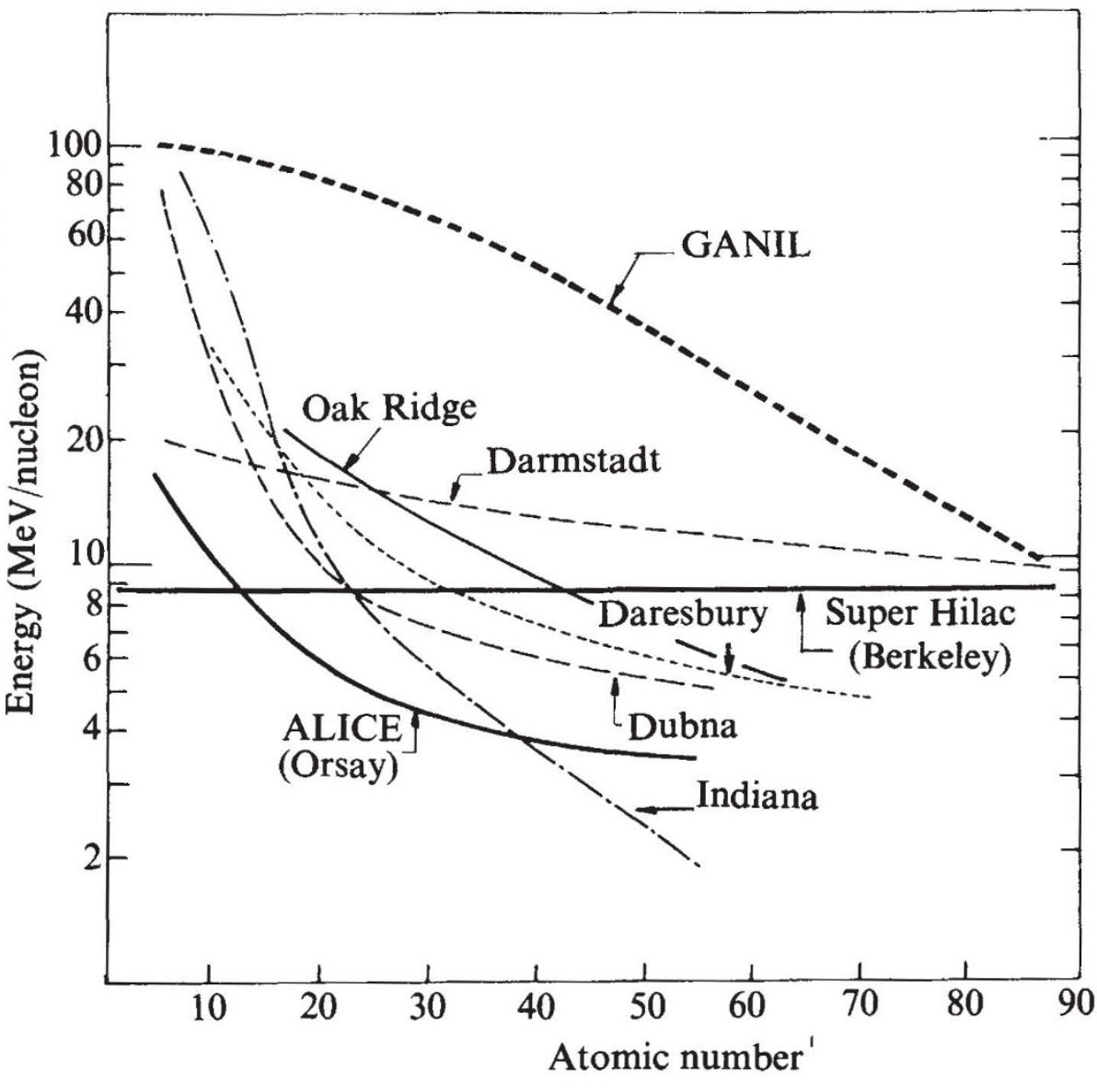

A comparison of the energy per nucleon available from GANIL (planned) compared with that available (or planned) at other accelerators.

dreamt up by a working party drawn from the CEA and IN2P3, and the money required will be provided in equal measure by the two organisations.

There are two somewhat unusual features of GANIL: first, that the main part of the system is to comprise two large cyclotrons, one of which will inject particles into the other, and second that superconducting magnets, which are increasingly in evidence in designs for new accelerators, are not to be used. As to the cyclotrons, the GANIL team maintains that it is only by using this kind of accelerator that high values of the energy per nucleon of a nucleus can be achieved. Certainly, if the promise implied in the figure is upheld, the French will have something to be proud of: over much of the range of atomic numbers the energy per nucleon available from GANIL is several times higher than from other accelerators.

The GANIL team decided against superconducting magnets mainly on the grounds that France does not have enough experience to take what might amount to a very risky step, especially as others have hit snags while building such magnets for accelerators. The team argues, however, that a cyclotron system is absolutely necessary and is to be preferred to the tandem Van de Graaff arrangements to be used at Daresbury in the UK, for example. Certainly the linear machines at Darmstadt and Berkeley, for example, are capable of accelerating greater numbers of particles per second, and the quality of the beam from a linear machine is on the whole better than from a cyclotron, but when it comes to increasing the energy delivered, the cyclotron seems to win hands down.

Not all users of GANIL will have to avail themselves of the maximum energy available, however. Many of the people who will eventually use the facility are chemists, biologists and so on, and it will often be that they will use beams of particles from the first cyclotron, before they are injected into the second one for further acceleration. In any event, the site for GANIL - which is still a green field on which no more than preliminary geological investigations have been made-is close to the Faculty of Medicine of the University of Caen, and to a college of technology; there is also ample room for interested industrial concerns like electronics companies to set up their own bases nearby so that they can make use of GANIL for their own investigations, on ion implantation, for example. 